\title{
ĐÁNH GIÁ HIỄU QUẢ HÓA XẠ TRỊ ĐồNG THỜI TRƯớC PHẪU THUẬT ĐIỀU TRI UNG THƯ TRỰC TRÀNG GIAI ĐOẠN II, III
}

\author{
Trương Thu Hiền*, Nguyễn Văn Ba*, Phạm Văn Thái*, \\ Dương Thùy Linh*, Trần Văn Tôn**
}

\section{TÓM TẮT}

Mục tiêu: Đánh giá hiệu quả hoá xạ trị̣ồng thời (HXTĐTT) trước phấu thuật (PT) trong điều trị (ĐT) ung thư trực tràng (UTTT) giai đoạn II, III đồng thời nhận xét một số tác dung không mong muốn và độc tính của phương pháp ĐT này. Đối tượng và phương pháp nghiên cứu: Nghiên cứu mồ tả hồi cứu kết hợp tiến cứu trên 48 bệnh nhân (BN) UTTT giai đoạn III, III được xạ trị liều 50,4 Gy kết hợp hóa chất Capecitabine liều $825 \mathrm{mg} / \mathrm{m} 2$ x 2 lần/ngày vào các ngày xa trị, phẫu thuật được thực hiện sau kết thúc HXTĐT 4-6 tuân. Kết quả: Tỷ lệ đáp ứng toàn bộ sau điều trị đạt $83,4 \%$. Tất cà bệnh nhân được phẫu thuật triệt căn trong đó $87,5 \%$ PT bảo tôn cơ thắt hậu môn. Đánh giá mô bệnh học của bệnh phẩm sau phẫu thuật: $25 \%$ đáp ứng hoàn toàn; $85,4 \%$ giảm giai đoạn u và $91,7 \%$ giảm giai đoạn hạch. Độc tính găp chủ yếu ở độ 1 : thiếu máu độ 1 là $39,6 \%$, giảm sổ lượng bạch cầu hạt trung tính độ 1 là 6,3\%. Các tác dụng không mong muốn khác hay gặp là viêm bàng quang độ $1(20,8 \%)$ và viêm da do xạ trị độ 1 $(37,5 \%)$. Không gặp độc tính độ 3,4 . Kết luận: HXTĐT trước phâuu thuậtvới Capecitabine là phướng pháp điều trị hiệu quả, an toàn và ít độc tính cho BN UTTT giai đoạn III, III. II, III

Tư khóa: Hóa xa trị, ung thư trực tràng, giai đoạn

\section{SUMMARY}

EVALUATION OF TREATMENT OUTCOME OF NEOADJUVANT CONCURRENT

\section{CHOMORADIATION THERAPY FOR WITH}

STAGE II AND III RECTAL CANCER

Objective: Evaluation of treatment outcomes of neoadjuvant concurrent chemoradiation therapy for patients with stage II and III rectal cancer and commented on some of the side effects and toxicity of this treatment. Subjects and methods: A descriptive retrospective combines prospective study in 48 patients with stage II and III rectal cancer who receive radiation therapy dose of $50.4 \mathrm{~Gy}$ in combination with Capecitabine at the dose of $825 \mathrm{mg} / \mathrm{m} 2 \times 2$ times/day on the days of radiation therapy, surgery is performed 4-6 weeks after the end of concurrent chemoradiation therapy. Results: The overall response rate after treatment reached $83.4 \%$.

\footnotetext{
*Bệnh viện Quân y 103

**Bênh viện Bạch Mai

Chịu trách nhiệm chính: Nguyễn Văn Ba

Email:bsnguyenvanba@yahoo.com

Ngày nhận bài: 25/2/20

Ngày phản biện khoa học:1/4/2021

Ngày duyệt bài: 15/4/2021
}

All patient underwent definitive surgery, of which $87.5 \%$ have surgery to preserve the anal sphincter. Evaluation of histopathology of the patient after surgery: $25 \%$ with a complete response; $85.4 \%$ downstage primary tumours and $91.7 \%$ downstage nodal. Toxicity is mainly encountered at level 1,2: grade 1 anaemia is $39.6 \%$, grade 1 leukopenia is $6,3 \%$. Other common side effects are grade 1 cystitis $(20.8 \%)$ and grade 1 radiation dermatitis (37.5\%). No toxicity degree 3,4. Conclusion: Concurrent chemoradiation therapy preoperative with Capecitabine is the effective, safe and less toxicity treatment for patients with stage II and III rectal cancer.

Keywords: Chemoradiation therapy, rectal cancer, stage II and III

\section{I. ĐĂT VẤN ĐỀ}

Ung thư trực tràng (UTTT) là một trong những loại ung thư đường tiêu hóa hay gặp tại Việt Nam và trên thế giới. Theo Globocan, năm 2020 tại Việt Nam, bệnh đứng thứ 5 trong những bệnh ung thư có số ca mới mắc cao nhất với 9399 ca và tỷ lệ tử vong của bệnh là 3,9\% [1]. Với UTTT giữa và thấp giai đoạn II, III hóa xạ trị đồng thời trước phẫu thuật là phương pháp điều trị chuẩn, giúp làm giảm giai đoạn bệnh, tăng tỷ lệ PT triệt căn và bảo tồn cơ thắt hậu môn [2], [3] , [4]. Tại Việt Nam hiện chưa có nhiều nghiên cứu về hiệu quả của phương pháp điều trị này. Vì thế, chúng tôi tiến hành thực hiện đề tài: "Đánh giá hiệu quả hoá xạ trị đồng thời trước phẫu thuật trong điều trị ung thư trực tràng giai đoạn II, III" với hai mục tiêu: 1) Đánh giá hiệu quả hoá xa trị đồng thời trước phẫu thuật vớiUTTT giai đoạn II, III. 2) Nhận xét một số tác dụng không mong muôn và độc tính của phương pháp DT này.

\section{II. ĐỐI TƯợNG VÀ PHƯƠNG PHÁP NGHIÊN CứU}

2.1. Đối tượng nghiên cứu: 48 bệnh nhân UTTT giai đoạn II, III được HXTĐT trước PT tại Bệnh viện Quân Y 103 và Bệnh viện Trung ương Quân Đội 108 từ 2018 - 2020.

2.2. Phương pháp nghiên cứu: Nghiên cứumô tả hồi cứu kết hợp tiến cứu.

\section{Các bước tiến hành:}

- BN được khám lâm sàng và thực hiện các xét nghiệm cận lâm sàng trước và sauphẫu thuật.

- Sau khi BN được chẩn đoán UTTT giai đoạn II,III theo phân loại TNM của hiệp hội ung thư Hoa Kì AJCC 2017, tiến hành điều trị. 
+ Hóa trị: Capecitabine $825 \mathrm{mg} / \mathrm{m}^{2}$ da uống hai lần một ngày trong các ngày xạ trị, nghỉ thứ 7 và chủ nhật.

+ Xa trị: tổng liều $50,4 G y$, phân liều 1,8Gy/ngày, 5ngày/tuần.

+ Phẫu thuật: được thực hiện sau khi kết thúc HXTĐT từ $4-6$ tuần.

- Đánh giá hiêu quả ĐT:

+ Đáp ứng lâm sàng: Dựa vào các triệu chứng cơ năng của $\mathrm{BN}$.

+ Đáp ứng trên cận lâm sàng: Dựa vào MRI tiểu khung theo tiêu chuẩn RECIST.

+ Đốc tính của HXTĐT: Dưa vào tiêu chuẩn đánh giá các biến cố bất lợi theo phiên bản 5.0 (Common Terminology Criteria for Adverse Events Version 5.0 - CTCAE) của Viện Ung thư quốc gia Hoa Kì năm 2017.

+ Tỷ lệ phẫu thuật triệt căn, tỷ lệ phẫu thuật bảotôn cơ thắt,đánh giá giai đoạn $u(y p T)$ và hạch di căn sau PT (ypN) theophân loại TNM của hiệp hội ung thư Hoa Kì AJCC 2017.

- Xỉ̛ lý số liệu: Bằng phần mềm SPSS 20.0

\section{KẾT QUẢ NGHIÊN CỨU}

3.1. Đánh giá hiệu quả điêu trị dựa vào các triệu chứng cớ năng

Bảng 1. Đáp ứng cơ năng sau điều tri

\begin{tabular}{|c|c|}
\hline $\begin{array}{c}\text { Triệu chứng được cải } \\
\text { thiện }\end{array}$ & Tỷ lệ \% \\
\hline Hết đại tiện phân nhầy máu & $37 / 46(80,4)$ \\
\hline Đại tiện phân thành khuôn & $17 / 24(70,8)$ \\
\hline $\begin{array}{c}\text { Số lần đại tieên giảm xuống } \\
\text { dưới } 3 \text { lần/ngày }\end{array}$ & $29 / 38(76,3)$ \\
\hline Hết táo bón & $10 / 19(52,6)$ \\
\hline
\end{tabular}

Nhân xét: Bệnh nhân cải thiện phần lớn triệu chứng trong và sau điều trị: hết đại tiện phân nhâyy máu $80,4 \%$; đại tiện phân thành khuôn 70,8\%.

3.2. Đánh giá hiệu quả điêu trị dựa trên MRI tiểu khung và giải phẫu bệnh

Bảng 2. Đáp ứng cơ năng sau điều tri \begin{tabular}{|l|l|l|}
\hline Giai đoạn & Trước điêuu trị & Sau điêuu trị \\
\hline
\end{tabular}

\begin{tabular}{|c|c|c|c|}
\hline \multirow{4}{*}{$\mathrm{T}$} & $\mathrm{Tx}$ & 0 & 10,0 \\
\cline { 2 - 4 } & $\mathrm{T} 1$ & 0 & $4(8,2)$ \\
\cline { 2 - 4 } & $\mathrm{T} 2$ & $1(2,1)$ & $12(25)$ \\
\cline { 2 - 4 } & $\mathrm{T} 3$ & $34(70,8)$ & $18(37,5)$ \\
\cline { 2 - 4 } & $\mathrm{T} 4$ & $13(27,1)$ & $4(8,3)$ \\
\hline \multicolumn{2}{|c|}{ Tống số } & $48(100)$ & $48(100)$ \\
\hline \multirow{4}{*}{$\mathrm{N}$} & $\mathrm{N} 0$ & $4(8,3)$ & $19(39,6)$ \\
\cline { 2 - 4 } & $\mathrm{N} 1$ & $13(27,1)$ & $22(45,8)$ \\
\cline { 2 - 4 } & $\mathrm{N} 2$ & $29(60,4)$ & $7(14,6)$ \\
\cline { 2 - 4 } & $\mathrm{N} 3$ & $2(4,2)$ & 0 \\
\hline \multicolumn{2}{|c|}{ Tống số } & $\mathbf{4 8 ( 1 0 0 )}$ & $\mathbf{4 8 ( 1 0 0 )}$ \\
\hline
\end{tabular}

Nhận xét: Sau HXTĐT, tỷ lệ BN không di căn hạch tăng 31,3\%. BN giai đoạn u T3, T4 giảm 52,1\%.

Bảng 3. Đáp giá đáp úng sau điều trị theo tiêu chuẩn RECIST

\begin{tabular}{|c|c|}
\hline Đáp ứng & Tỷ lệ \% \\
\hline Đáp ứng hoàn toàn & 6,3 \\
\hline Đáp ứng một phần & 77,1 \\
\hline Bệnh ốn định & 12,5 \\
\hline Bẹ̣nh tiến triến & 4,2 \\
\hline
\end{tabular}

Nhận xét: Tỷ lê đáp ứng toàn bộ là $83,4 \%$ trong đó có $6,3 \%$ bệnh nhân có đáp ứng hoàn toàn.

Bảng 4. So sánh giai đoạn u trên MRI trước HXTET và GPB

\begin{tabular}{|c|c|c|c|c|c|}
$\begin{array}{r}\text { Trước } \\
\text { HXTĐT } \\
\text { pT }\end{array}$ & T1 & T2 & T3 & T4 & $\begin{array}{c}\text { Tổng } \\
\text { số }\end{array}$ \\
\hline T0 & 0 & 0 & $9(18,7)$ & $3(6,2)$ & $12(25)$ \\
\hline T1 & 0 & 0 & $7(14,6)$ & $1(2,1)$ & $8(16,7)$ \\
\hline T2 & 0 & $1(2,1)$ & $12(25)$ & $3(6,3)$ & $16(33,3)$ \\
\hline T3 & 0 & 0 & $6(12,5)$ & $6(12,5)$ & $12(25)$ \\
\hline T4 & 0 & 0 & 0 & 0 & 0 \\
\hline
\end{tabular}

Tổng số $\quad 0 \quad 1(2,1) 34(70,8) 13(27,1)$ 48(100)

Nhận xét: Có $12 / 48(25 \%)$ bênh nhân đáp ứng hoàn toàn trên mô bệnh học, $41 / 48$ (85,4\%).

Bảng 5. So sánh giai đoạn hạch trên MRI trước HXTET và GPB

\begin{tabular}{|c|c|c|c|c|c|}
$\begin{array}{r}\text { Trước } \\
\text { HXTÐT } \\
\text { pN }\end{array}$ & N0 & N1 & N2 & N3 & $\begin{array}{c}\text { Tổng } \\
\text { số }\end{array}$ \\
\hline N0 & 4 & 13 & 24 & 2 & 43 \\
$(8,3)$ & $(27,1)$ & $(50)$ & $(4,2)$ & $(89,6)$ \\
\hline N1 & 0 & 0 & $\begin{array}{c}5 \\
(10,4)\end{array}$ & 0 & $\begin{array}{c}5 \\
(10,4)\end{array}$ \\
\hline N2 & 0 & 0 & 0 & 0 & 0 \\
\hline N3 & 0 & 0 & 0 & 0 & 0 \\
\hline Tổng số & 4 & 13 & 29 & 2 & 48 \\
$(8,3)$ & $(21,1)$ & $(60,4)$ & $(4,2)$ & $(100)$ \\
\hline
\end{tabular}

Nhân xét: Bệnh nhân giảm giai đoạn hạch sau HXTĐT là 44/48 (91,7\%).

3.3. Kết quả phâuu thuâat

Bảng 6. Phương pháp phẫu thuật sau HXT

\begin{tabular}{|c|c|c|c|}
\hline \multicolumn{2}{|c|}{$\begin{array}{c}\text { Phương pháp phẫu } \\
\text { thuật }\end{array}$} & $\begin{array}{l}\text { TT trung } \\
\text { bình }\end{array}$ & TT thấp \\
\hline \multirow{3}{*}{ Triệt căn } & $\begin{array}{c}\text { Bảo tồn cơ thắt } \\
\text { hậu môn }\end{array}$ & $\begin{array}{c}26 \\
(100)\end{array}$ & $\begin{array}{c}16 \\
(72,7)\end{array}$ \\
\hline & $\begin{array}{c}\text { Phấu thuật } \\
\text { Miles }\end{array}$ & 0 & $\begin{array}{c}6 \\
(27,3)\end{array}$ \\
\hline & Hartmann & 0 & 0 \\
\hline $\begin{array}{l}\text { Không } \\
\text { triệt cănn }\end{array}$ & HMNT trên u & 0 & 0 \\
\hline \multicolumn{2}{|c|}{ Tống } & $26(54,2)$ & $22(45,8)$ \\
\hline
\end{tabular}

Nhân xét: Tất cả bệnh nhân đều được phầu thuật triệt căn. Nhóm bệnh nhân UTTT thấp có $72,7 \%$ BN được phẫu thuật triệt căn có bảo tồn 
cơ thắt hậu môn.

3.4. Các tác dụng không mong muốn trong và sau HXT

Bảng 7. Độc tính trên hệ huyết học, gan, thận

\begin{tabular}{|c|c|c|}
\hline $\begin{array}{l}\text { Độ̂ tính trên } \\
\text { hệ huyết học }\end{array}$ & $\begin{array}{l}\text { Phân đố } \\
\text { độc tính }\end{array}$ & n (\%) \\
\hline \multirow{5}{*}{ Hemoglobin } & 0 & $25(52)$ \\
\hline & 1 & $19(39,6)$ \\
\hline & 2 & $4(8,4)$ \\
\hline & 3 & 0 \\
\hline & Tống & $48(100)$ \\
\hline \multirow{5}{*}{ Tiểu câu } & 0 & $43(89,6)$ \\
\hline & 1 & $5(10,4)$ \\
\hline & 2 & 0 \\
\hline & 3 & 0 \\
\hline & Tống & $48(100)$ \\
\hline \multirow{5}{*}{$\begin{array}{l}\text { Bach cầu hạt } \\
\text { trung tính }\end{array}$} & 0 & $43(89,6)$ \\
\hline & 1 & $5(10,4)$ \\
\hline & 2 & 0 \\
\hline & 3 & 0 \\
\hline & Tống & $48(100)$ \\
\hline \multirow{4}{*}{ Creatinin } & 0 & $47(97,9)$ \\
\hline & 1 & $1(2,1)$ \\
\hline & 2 & 0 \\
\hline & Tống số & $48(100)$ \\
\hline \multirow{4}{*}{ GOT } & 0 & $42(87,5)$ \\
\hline & 1 & $6(12,5)$ \\
\hline & 2 & 0 \\
\hline & Tống số & $48(100)$ \\
\hline
\end{tabular}

Nhân xét: Độc tính trên hê huyết hoc ít, chủ yếu là độ 1 với tỷ lệ $39,6 \%$ và $6,3 \%$ tương ứng với hemoglobin và bạch cầu hạt trung tính. Độc tính trên gan thận chi gặp độ 1 với tỷ lệ $12,5 \%$ và $2,1 \%$ tương ứng.

Bảng 8. Các tác dụng không mong muốn khác Các tác dụng không mong muốn $\mathbf{n}(\%)$

\begin{tabular}{|c|c|}
\hline & \\
\hline Buồn nôn độ 1 & $7(14,6)$ \\
\hline Tiêu chảy độ 1 & $3(6,3)$ \\
\hline HC bàn tay - bàn chân độ 1 & $3(6,3)$ \\
\hline $\begin{array}{c}\text { Viêm niêm mạc ống hậu môn, trực } \\
\text { tràng đô } 1\end{array}$ & $5(10,4)$ \\
\hline Loét hậu môn, trực tràng độ 1 & $2(4,2)$ \\
\hline Viềm bàng quang độ 1 & $10(20,8)$ \\
\hline Viêm âm đạo độ 1 & $1(4,8)$ \\
\hline Viêm da do xạ trị độ 1 & $18(37,5)$ \\
\hline Viêm da do xạ trị độ 2 & $2(4,2)$ \\
\hline $\begin{array}{l}\text { Loét da độ } 1 \\
\text { Lét da đồ }\end{array}$ & $3(6,3)$ \\
\hline & \\
\hline
\end{tabular}
độ 1,2 .

\section{BÀN LUÂ̂N}

Sau HXTĐT, $100 \%$ bệnh nhân đều cho biết có cải thiện các triệu chứng lâm sàng. Trong đó, hết đại tiện phân nhây máu $80,4 \%$; đại tiện phân thành khuôn 70,8\%; số lần đại tiện giảm xuống dưới 3 lần/ngày 76,3\%; hết táo bón $52,6 \%$. Nghiên cứu của các tác giả kháccho thây triệu chứng đại tiện ra nhây máu cải thiện 83,3 $86,6 \%$; đi ngoài phân thành khuôn 72,4 $73,3 \%$; số lần đại tiện giảm xuống dưới 3 lần/ngày 88-89,7\%; hết táo bón 73,3\% [5],[6]. Sự khác biệt này là do nghiên cứu của chúng tôi lựa chọn các bệnh nhân UTTT trung bình và thấp nên tỷ lệ bệnh nhân táo bón và đại tiện nhiêu lần trong ngày ít hơn $\mathrm{BN}$ có khối u trực tràng thấp trong nghiên cứu của các tác giả trên.

Tỷ lệ BN có khối u trực tràng có giai đoạn T3 và T4 trên MRI tiểu khung giảm 52,1\%. Số lượng hạch vùng di căn cũng giảm đáng kể. Sau HXTĐT,tỷ lệ BN không có di căn hạch vùng tăng $31,3 \%$. Kết quả này cao hơn kết quả của tác giả Nguyễn Văn Hiếu là 32,2\% và 25,7\% tương ứng do nhóm BN trong nhóm nghiên cứu của chúng tôi có giai đoạn bệnh sớm hơn [6].

Toàn bộ 48 BN được phẫu thuât triêt căn. Trong nhóm BN UTTT trung bình 100\% BN được PT bảo tồn cơ thắt hậu môn. Đối với nhóm BN UTTा thấp có $72,7 \%$ BN được PT bảo tồn cơ thắt hậu môn. Kết quả của chúng tôi tương đương với kết quả nghiên cứu của tác giả khác. Tác giả de Bruin và cs (2008) tất cả các BN đều được PT triệt căn, với nhóm BN UTTT thấp có $75 \%$ BN được PT bảo tổn cơ thắt [7]. Tỷ lê PT bảo tổn cơ thắt của Nguyễn Xuân Kiên và cs là $69,2 \%$ [8].

Bệnh phẩm sau PT được đánh giá kết quả mô bênh học cho thây $25 \%$ đáp ứng hoàn toàn; $85,4 \%$ giảm giai đoạn u và $91,7 \%$ giảm giai đoạn hạch. Kết quả này của chúng tôi cao hỡn kết quả nghiên cứu của một số tác giả Nguyễn Xuân Kiên. Các tỷ lệ là $15,4 \%, 51,9 \%$ và $66,36 \%$ tương ứng [8].

Độc tính trên hệ huyết học gặp chủ yếu ở độ 1. Nồng độ hemoglobin giảm độ 1 là $39,6 \%$. Chỉ có $8,4 \%$ BN có giảm hemoglobin đô 2 . Giảm tiểu cầu độ 1 là 10,4\%. Tỷ lệ BN có số lượng bạch cầu hạt trung tính giảm độ 1 là 10,4\%.Độc tính trên gan, thận chỉ gặp ở độ 1 với tỷ lệ $2,1 \%$ và $12,5 \%$ tương ứng.

Các tác dụng không mong muốn khác chỉ gặp ở độ 1 và 2 , hay gặp là viêm niêm mạc ống hậu môn, trực tràng độ $1(10,4 \%)$, buồn nồn $(14,6 \%)$, viêm bàng quang độ $1(20,8 \%)$ và viêm da do xạ trị độ $1(37,5 \%)$. Các TDKMM khác như loét hậu môn, trực tràng độ 1 , viêm da do xạ trị độ $2(4,2 \%)$, tiểu chảy độ $1, \mathrm{HC}$ bàn tay - bàn chân độ 1 , loét da độ $1(6,3 \%)$. Kết quả này tương đương với kết quả nghiên cứu của các tác giả khác [5], [8]. 


\section{KẾT LUẬN}

HXTĐT với Capecitabine trước phẫu thuât là phương pháp điêu trị hiệu quả. Tỷ lệ đáp ứng toàn bộ sau điều trị đạt 83,4\%, tỷ lệ BN được PT triệt căn là $100 \%$ trong đó có $85,4 \%$ BN được PT bảo tôn cơ thắt hậu môn. Điều trị HXTĐT tiển phẫu cho bệnh nhân UTTT giai đoạn II, III là phương pháp điều trị an toàn và ít độc tính.

\section{TÀI LIÊU THAM KHẢO}

1. International Agency for Research on Cancer (2020), Globocan 2020: Estimated Cancer Incidence, Mortality and Prevalence Worldwide in 2020.

2. NCCN (2019), Rectal Cancer, Clinical Practice Guidelines in Oncology.

3. Kinjal Parikh, Albert S. DeNittis, Gerald Marks et al., (2019), "Neoadjuvant chemotherapy and high-dose radiation using intensity-modulated radiotherapy followed by rectal sparing TEM for distal rectal cancer", Journal of Radiation Oncology, 8(2), pp. 217-224.

4. William Chapman, Hyun Kim, Philip Bauer et al., (2019), "Total neoadjuvant therapy with short course radiation compared to concurrent chemoradiation in rectal cancer", Journal of Clinical Oncology, 37(4_suppl), pp. 468-486.

5. Pham Cẩm Phương (2013), Đánh giá hiệu quả hoá xạ trị kết hợp Capecitabine trưỡc mổ trong ung thư trực tràng thấp tiến triển tại chố, Luận văn Tiến sĩ y hợc, Chuyên ngành ung thư', Đại học Y Hà Nội.

6. Nguyễn Văn Hiếu, Lê Văn Quảng, Bùi Cổng Toàn et al., (2018), "Đánh giá kết quả hóa xạ trị tiền phẩu trong ung thư trực tràng giai đoạn xâm lấn", Tạp chí khoa học công nghệ Việt Nam, 60(2), pp. 1-4.

7. de Bruin AF, Nuyttens JJ, Ferenschild FT et al., (2008), "Preoperative chemoradiation with capecitabine in locally advanced rectal cancer", Neth J Med, 66(2), pp. 71-76.

8. Nguyễn Xuân Kiên, Nguyễn Đình Châu, Nguyê̂n Thị Hà et al., (2017), "Đánh giá kết quá điểu tri hóa xa tri tiền phấu với capecitabine ở bệnh nhân ung thư trực tràng giai đoạn tiến triển còn khả năng phâuu thuât tai Bênh viên Trung ương Quân đội 108", Tạp chí Ỳ dược lẩm sàng 108, 12(9), pp. 135-140.

\section{ỨNG DỤNG VẠT DA CÂN THƯỢNG ĐÒN CÓ NỐI MACH VI PHẪU TAI ĐẦU XA TRONG TA O HÌNH SẸO DI CHỨNG BỎNG VÙNG CỔ}

\section{TÓM TẮT}

Mục tiêu: Che phủ khuyết rộng toàn bộ vùng cằm cổ, sử dung nhánh xuyên tại đầu xa của vat da cân thượng đòn nhằm tăng kích thước của vat là phương pháp hiệu quả, có tính ứng dụng cao. Đối tượng và phương pháp: 30 bệnh nhân có sẹo co kéo nặng vùng cổ được phẩu thuât sử dung vạt da cân thượng đòn có nối vi phẫu tai đầu xa từ năm 2014 đến 2020. Vạt được nối vi phẫu tại đâu xa sử dụng nhánh xuyên của động mach cùng vai ngực sau khi phấu tích vạt nâng vạt. Kết quả: Toàn bộ 30 vạt da sống hoàn toàn, chiều dài vạt đat tối đa $28 \mathrm{~cm}$ và chiều rộng tối đa $25 \mathrm{~cm}$. Theo dõi ở thời điểm 3 tháng sau mổ có $29 / 30$ bệnh nhân $(96,67 \%)$ hài lòng với kết quả sau mổ. Đánh giá ở thời điểm sau mổ 6 tháng, tất cả các bệnh nhân đều hài lòng với kết quả phẫu thuật. Kết luâan: Vạt da cân thượng đòn có nối mạch vi phẩu tai đâu xa là lựa chọn tối ưu trong tao hình các tổn khuyết rộng vùng cổ, đặc biệt là tạo hình sẹo di chứng bỏng.

Tự khóa: Vạt da cân thượng đòn, vạt có nối mạch vi phẩu tại đầu xa

\section{SUMMARY}

*Bệnh viện Bỏng Quốc gia Lê Hữu Trác Chịu trách nhiệm chính: Tống Thanh Hải Email: drtonghai@gmail.com Ngày nhận bài: 25/2/2021 Ngày phản biện khoa học: 12/3/2021 Ngày duyệt bài: 1/4/2021

\section{EXPANDING THE DIMENSIONS OF FLAP, SUPERCHARGING AT DISTAL PART OF FLAP WAS THE NEW POWERFUL PROCEDURE}

Purpose: To expand the dimension of flap, supercharging at distal part of flap was the new powerful procedure. Subjects and methods: 30 patients suffered from severe contructure scar in neck region were operated by using supercharged supraclavicular flap between 2014 and 2020. The thoracoacromial vessel was choiced to anatomosis at distal part after flap elevation. Results: All of flaps were survived completely, the maximum dimension of flap was $28 \mathrm{~cm}$ in length and $25 \mathrm{~cm}$ in width. Following up at 3 months postoperation, twenty-nine of the 30 patients were satisfied with both the functional and aesthetic results. All patients were satisfiedat 6 months after surgery. Conclusion: The supercharged supraclavicular flap was the optimized choice to reconstruct of neck region, especiallyfor severe defects after burn.

Keyword: supraclavicular flap, supercharged supraclavicular flap

\section{I. ĐĂT VẤN ĐỀ}

Vùng cổ là vùng có biên độ vận động rất lớn theo nhiều hướng khác nhau. Chính vì vậy, sau phẫu thuật chỉnh sửa sẹo, nguy cơ co kéo dễ có xu hướng tái phát. Thêm nữa, vùng cổ không chỉ là một vùng cần đảm bảo về chức năng mà còn rất quan trọng về mặt thẩm mỹ. Các vạt da lân cận vùng cổ luôn là lựa chọn được ưu tiên hàng 